\title{
Women empowerment through health seeking behavior in Bangladesh: Evidence from a national survey
}

\author{
Md. Nazmul Hasan ${ }^{1}$, M Sheikh Giash Uddin ${ }^{2}$
}

${ }^{1}$ MSc Student; ${ }^{2}$ Associate Professor; Department of Statistics, Jagannath University, Dhaka, Bangladesh.

\section{Abstract}

Empowering women is an important subject to achieve targets for the Sustainable Development Goals (SDGs) of Bangladesh. There are several indicators to measure the empowerment of women. Health seeking information is one of the most important indicators in this regard. This study aims at identifying the levels and patterns of women empowerment in relation to health seeking behavior in Bangladesh. Bangladesh Demographic and Health Survey (BDHS) 2011 data was used for the study. A total of 16635 women of reproductive age were included in this study. Only $42 \%$ of recently married women participated in all the four discussions regarding their own health care, major household purchases, child health care, and visiting their family or relatives. Cross tabulation and logistic regression analyses were performed to know about women empowerment in relation to health seeking behavior on decision making, controlling the effect of other independent variables. The results showed that about $63 \%$ women were empowered (either by themselves or jointly with their husbands) to decide on their own healthcare seeking and around $67 \%$ in healthcare seeking for their children. Working women were 1.734 times more likely to seek their own healthcare than non-working women. Again rural women appeared to be $21 \%$ less likely to seek child healthcare compared to urban women. The results of this study showed that seeking health information empowered women to promote their self-confidence, filter the information, manage life problems successfully, feel strength against health problems and disabilities, and be encouraged to seek more information.

Keywords: Women empowerment, Decision-making, Health seeking behavior, BDHS, Bangladesh.

\section{Introduction}

On 1 January 2016, the 17 Sustainable Development Goals (SDGs) of the 2030 Agenda for Sustainable Development - adopted by world leaders in September 2015 at a historic UN Summit — officially came into force. The target 5.5 of SDG 5 is to ensure women's full and effective participation and equal opportunities for leadership at all levels of decision making in political, economic and public life. ${ }^{1}$ Empowerment of women is essential for the achievement of sustainable development. The ability of women to make decisions that affect the personal circumstances of their own lives is an essential aspect of women empowerment and serves as an important contributor to their overall welfare. ${ }^{2}$ Empowered women can more successfully negotiate their reproductive and health related performances with male partners. $^{3}$

Women's empowerment expands the freedom of choice action to shape women's lives. ${ }^{4}$ Women empowerment is considered as a necessary condition for development, although it is not a sufficient condition. ${ }^{5}$ Women empowerment has several dimensional focuses and envisages greater access to knowledge, social and economic resources, and greater participation in economic and political decision-making processes. ${ }^{6}$ It seeks change in the sexual division of labor, equal access to food, healthcare, education, employment opportunities, ownership of land and other assets, and access to the media. ${ }^{7}$ Evidences show that women lag behind men in many aspects of development such as educational attainment, employment, social and political power, and exposure to the media. ${ }^{8}$ At present, Bangladesh has progressed in

\section{Practice Points}

- Empowerment of women is essential for achievement of sustainable development.

- Less than half (42\%) of currently married women participated in all four discussions regarding their own healthcare, child healthcare, major households purchases, and visits to their family or relatives'.

- Women's age, their occupation, place of residence and NGO membership had a significant association with women's empowerment in deciding all four discussions.

- Educated women (secondary ${ }^{+}$) were 1.35 times more likely to seek their own healthcare and 1.57 times more likely to seek child healthcare than those of non-educated women.

- Women's participation in workforce should be increased so that women can be self-dependent financially and their participation in decision-making would be encouraged.

terms of women empowerment. ${ }^{9}$ The 2011 Global Gender Gap Index developed by the World Economic Forum, ranks Bangladesh as 69 th out of 135 countries in terms of gender equality. ${ }^{10}$

Previous studies showed that empowerment of patients resulted in favorable health outcomes, such as increased power of decision-making, freedom of

Correspondence: Md. Nazmul Hasan, MSc Student, Department of Statistics, Jagannath University, Dhaka, Bangladesh. Email: nazmul.nobel@gmail.com. 
making choices and accepting the responsibility. ${ }^{11,12}$ Moreover, the process also helped to develop trust in relations; inform choices; facilitate adaptation, well-beings, and hopefulness; increase speed of personal developments and awareness of one's own world; identify one's own strengths and abilities; feel more powerful, higher self-confidence, higher personal satisfaction, higher self-efficiency; and eventually improve quality of life. ${ }^{13,14}$

Health information seeking behavior can promote health knowledge and consequently formulate the judgments, believes, acquisition of adequate knowledge for identifying the alternatives and available resources for doing different activities and taking into account the positive and negative aspects of issues. ${ }^{15}$ In this respect, it is necessary to empower patients toward acquiring, processing, and understanding the basic health information. ${ }^{16}$ The available literature in this regard mentioned various capabilities as the outcomes of seeking health information.

However, few studies have been performed on seeking health information in general and health information seeking behavior in particular in Bangladesh. The aim of this study was to identify the levels and differentials in women's empowerment in terms of decision-making authority in relation to health seeking behavior in Bangladesh. The study also examined the relationship between women empowerment and health seeking behavior in Bangladesh. The findings may be a tool in hand for policy makers in implementing policies, which might raise the status of women and should help to achieve the targets for the Sustainable Development Goals (SDGs).

\section{Materials and methods}

The study used data from Bangladesh Demographic and Health Survey (BDHS) 2011. ${ }^{17}$ The survey followed a stratified two-stage cluster sample design based on the 2001 census. At the first stage, 600 primary sampling units (PSU) are selected consisting of 393 rural and 207 urban units with probability proportional to size (PPS). At the second stage, a random sample of households is selected from each of the PSU and all ever-married women of the selected households are interviewed by using systematic random sampling technique.

Univariate and bivariate analyses are used for descriptive measures. Bivariate relationships between dependent and independent variables are examined by using Chi-square test of association. To identify the factors influencing women's empowerment, binary logistic regression was carried out. Four models were estimated, in the first we estimated women's empowerment in own health care (yes $\left.=1, \mathrm{no}^{\prime}=0\right)$, in the second model we estimated women's empowerment in child health care, in the third model we estimated women's empowerment in large household purchase, and in the fourth model we estimated women's empowerment in visiting relatives' homes as dependent variable and various independent (demographic, socioeconomic and program) variables. Women's empowerment is defined as the decision was taken either by themselves or jointly with their husbands. The model examines the effects of demographic and other socio-economic characteristics on the likelihood of women empowered. In the analysis of the model, women's empowerment is measured as dichotomous variable coded 1 if a woman decided (about own healthcare, child healthcare, large household purchase, and visiting relatives' homes) on the date of interview and 0 otherwise. Logistic regression model is used for the analysis. ${ }^{18}$ The coefficients in the analysis represent an increase or decrease in the log odds of being occurrence of an event (versus not occurrence) associated with a unit or category change in an independent variable.

The mathematical model is expressed as:

$$
\operatorname{Ln}\left(\frac{p_{i}}{1-p_{i}}\right)=\beta_{0}+\beta_{1} x_{1}+\beta_{2} x_{2}+-----+\beta_{n} x_{n}
$$

where, $P\left(Y_{i}=1\right)=p_{i}$ and $P\left(Y_{i}=0\right)=1-p_{i} ; \mathrm{X}_{\mathrm{i}}=$ Independent variables such as woman's demographic, socio economic and program related characteristics, $b_{0}=$ Intercept term of the regression model, $b_{\mathrm{i}}=$ Regression co-efficient of the respective variable, representing the effect or association for individual characteristics.

\section{Results}

A total of 16635 recently married women; aged 15-49 years participated in this study. About $32 \%$ of the participants were aged $<25$ years old followed by $19 \%$, $28 \%, 21 \%$ aged $25-29$ years, $30-39$ years, and $\geq 40$ years respectively. Only $74 \%$ of the women had some years of formal education. A total of $30.2 \%$ had primary education whereas $43.5 \%$ had secondary+ education. Among the participants, only $13.3 \%$ had some sorts of formal work and rest of them $(86.7 \%)$ were housewives. Almost $90 \%$ of the participants were Muslim; while $10 \%$ had other religions. About one-third (35.9\%) women were members of some NGO and only $12.6 \%$ were married for $\geq 18$ years. However, it was apparent that $63.1 \%$ women had power (either by themselves or jointly with their husbands) in deciding their own healthcare seeking, $66.7 \%$ in healthcare seeking for their children, $59.6 \%$ in spending resources on major households items, and $62.7 \%$ in visiting relatives' homes. The socio-economic and empowerment status are summarized in Table 1.

The results of cross-tabulation for women's empowerment in decision making and socio-economic characteristics are presented in Table 2. Besides women's working status, women's age, age at marriage, women's and partner's education, residing place, and NGO membership had a significant association with women's empowerment in deciding their own healthcare seeking. Women's empowerment in deciding child healthcare seeking seems to be associated with their age, occupation, place of residence, NGO membership, and religion. Signification association was also found between women's empowerment in deciding large households purchase and women's age, their occupation, NGO membership and place of residence.

The logistic regression analysis revealed that there were differences in terms of significant variables and their level of significance (Table 3). Husband's education is no longer significant with women's empowerment in deciding their healthcare seeking. Working women were 
Table 1: Socio-economic characteristics of the respondents $(\mathrm{n}=16635)$

\begin{tabular}{|c|c|}
\hline Variables & Respondents (\%) \\
\hline \multicolumn{2}{|c|}{ Age of the respondent's (years) } \\
\hline$<25$ & $5322(32 \%)$ \\
\hline $25-29$ & $3262(19.6 \%)$ \\
\hline $30-39$ & $4613(27.7 \%)$ \\
\hline$\geq 40$ & $3438(20.7 \%)$ \\
\hline \multicolumn{2}{|c|}{ Respondent's age at marriage } \\
\hline$<18$ & $14542(87.4 \%)$ \\
\hline$\geq 18$ & $2094(12.6 \%)$ \\
\hline \multicolumn{2}{|c|}{ Respondent's education } \\
\hline No education & $4379(26.3 \%)$ \\
\hline Primary & $5019(30.2 \%)$ \\
\hline Secondary + & $7237(43.5 \%)$ \\
\hline \multicolumn{2}{|l|}{ Husband's education } \\
\hline No education & $4996(30.0 \%)$ \\
\hline Primary & $4575(27.5 \%)$ \\
\hline Secondary + & $7056(42.4 \%)$ \\
\hline \multicolumn{2}{|c|}{ Respondent's Occupation } \\
\hline Housewife & $14425(86.7 \%)$ \\
\hline Others & $2210(13.3 \%)$ \\
\hline \multicolumn{2}{|c|}{ Type of place of residence } \\
\hline Urban & $4292(25.8 \%)$ \\
\hline Rural & $12343(74.2 \%)$ \\
\hline \multicolumn{2}{|l|}{ NGO membership } \\
\hline No & $10666(64.1 \%)$ \\
\hline Yes & $5964(35.9 \%)$ \\
\hline \multicolumn{2}{|l|}{ Respondent's religion } \\
\hline Islam & $14971(90.0 \%)$ \\
\hline Others & $1665(10.0 \%$ \\
\hline \multicolumn{2}{|c|}{ Empowerment in own healthcare seeking } \\
\hline Not decided & $6131(36.9 \%)$ \\
\hline Decided & $10486(63.1 \%)$ \\
\hline \multicolumn{2}{|c|}{ Empowerment in child healthcare seeking } \\
\hline Not decided & $5529(33.3 \%)$ \\
\hline Decided & $11079(66.7 \%)$ \\
\hline \multicolumn{2}{|c|}{ Empowerment in large household purchase } \\
\hline Not decided & $6717(40.4 \%)$ \\
\hline Decided & $9900(59.6 \%)$ \\
\hline \multicolumn{2}{|c|}{ Empowerment in visiting relatives home } \\
\hline Not decided & $6186(37.3 \%)$ \\
\hline Decided & $10414(62.7 \%)$ \\
\hline
\end{tabular}

significantly more $(\mathrm{OR}=1.73, \mathrm{p}<0.001)$ likely to seek their own healthcare. Women's age, their education (secondary+), and place of residence had a significant impact on women's decision making about own healthcare seeking. Rural women appeared to be less likely $(\mathrm{OR}=0.795, \mathrm{p}<0.001)$ to seek child healthcare compared to urban. Working women, their age, education, and NGO membership appeared to affect women's empowerment in child healthcare seeking significantly. The significant impact on women's empowerment in deciding major household purchases appeared with women's age, education, husband's education (secondary+), occupation, place of residence and NGO membership. After controlling the effect of other independent variables age group $\geq 40$ years were significantly more likely $(\mathrm{OR}=2.22, \mathrm{p}<0.001)$ to be empowered in deciding about visiting relatives home. Women's working status, their education (secondary + ), place of residence, and NGO membership also had significant effect on women's decision making about visiting relatives' homes.

\section{Discussion}

In this study, we identified the levels and patterns of women empowerment in relation to health seeking behavior in Bangladesh. A good number of participants in our study reported empowerment in deciding own healthcare, healthcare for children, deciding major households purchasing, and visiting relatives homes respectively. A study conducted by National Institute of Population Research and Training (NIPORT) in 2007, reported 55.8\% women decided own healthcare, $64 \%$ children's healthcare, $63.6 \%$ for major households purchases, and $58.7 \%$ for visiting relatives' homes. ${ }^{2}$ These findings also suggest that women empowerment is increasing day by day.

Different socio-economic factors affect women's decision-making patterns. Women aged $\geq 25$ years were significantly more empowered in deciding own healthcare, child healthcare, large households purchasing, and visiting relatives compared to women $<25$ years. But these findings of this study are inconsistent with other studies where it has been argued that women aged $\geq 25$ years were more likely to maintain the traditional gender roles of husband and wife and less likely to consider extra-familial demands even if it becomes own healthcare matters. ${ }^{9}$ This may because, approximately one-third of the participants were aged $<25$ years and around $74 \%$ of them were rural women.

This study found that women married at less than 18 years had more empowerment (except decision-making authority in visiting relatives' homes) which is inconsistent with previous studies. ${ }^{7}$ However, statistical significance was found only in empowerment in deciding child healthcare. It is likely that women married at $\geq 18$ years are also likely to have better education and have a higher likelihood of outgoing behavior due to delayed marriage.

Women's education had a significant impact on women's empowerment in deciding women's own healthcare (for secondary + ), deciding child healthcare, purchasing large households items, and visiting relatives (for secondary + ). These findings of this study are consistent with other studies where it has been argued that schooling for girls and enrollment rates reduce gender inequality in education. ${ }^{19,20}$ Similarly husband's education had a significant impact on women's empowerment. Women whose husbands had some years of formal education were less empowered in terms of decision making for child healthcare, and major household purchases except empowerment in deciding own healthcare seeking. It is likely that naturally educated husbands are more self-confident making them more authoritative than non-educated husbands.

Working women had higher empowerment and results were statistically significant for each case. Women employment is considered as an important determinant of women empowerment. ${ }^{5,21}$ Most probably, working women are more competitive while competing for roles gives women greater excess to 
Table 2: Distribution of women (aged 15-49 years) in relation to women's empowerment in decision making by their socio-economic characteristics $(n=16,635)$

\begin{tabular}{|c|c|c|c|c|c|c|c|c|}
\hline \multirow{2}{*}{$\begin{array}{l}\text { Socio-economic } \\
\text { variables }\end{array}$} & \multicolumn{2}{|c|}{ EHS } & \multicolumn{2}{|c|}{ ECHS } & \multicolumn{2}{|c|}{ ELHP } & \multicolumn{2}{|c|}{ EVRH } \\
\hline & $\begin{array}{c}\text { Not } \\
\text { decided } \\
36.9 \%\end{array}$ & $\begin{array}{c}\text { Decided } \\
63.1 \%\end{array}$ & $\begin{array}{c}\text { Not de- } \\
\text { cided } \\
\mathbf{3 3 . 3 \%}\end{array}$ & $\begin{array}{c}\text { Decided } \\
66.7 \%\end{array}$ & $\begin{array}{c}\text { Not } \\
\text { decided } \\
\mathbf{4 0 . 4 \%}\end{array}$ & $\begin{array}{c}\text { Decided } \\
59.6 \%\end{array}$ & $\begin{array}{c}\text { Not } \\
\text { decided } \\
\mathbf{3 7 . 3 \%}\end{array}$ & $\begin{array}{c}\text { Decided } \\
62.7 \%\end{array}$ \\
\hline \multicolumn{9}{|c|}{ Respondent's age (years) } \\
\hline$<25$ & $46.9 \%$ & $53.1 \%$ & $49.2 \%$ & $50.8 \%$ & $51.9 \%$ & $48.1 \%$ & $48.2 \%$ & $51.8 \%$ \\
\hline $25-29$ & $33 \%$ & $67 \%$ & $26.8 \%$ & $73.2 \%$ & $38.6 \%$ & $61.4 \%$ & $36.1 \%$ & $63.9 \%$ \\
\hline $30-39$ & $29.7 \%$ & $70.3 \%$ & $23.3 \%$ & $76.7 \%$ & $32.5 \%$ & $67.5 \%$ & $30.3 \%$ & $69.7 \%$ \\
\hline \multirow[t]{2}{*}{$\geq 40$} & $34.7 \%$ & $65.3 \%$ & $28.2 \%$ & $71.8 \%$ & $35 \%$ & $65 \%$ & $30.9 \%$ & $69.1 \%$ \\
\hline & \multicolumn{2}{|c|}{$\chi^{2}=385.2 ; p<0.01$} & \multicolumn{2}{|c|}{$\chi^{2}=913.9 ; p<0.01$} & \multicolumn{2}{|c|}{$\chi^{2}=454.7 ; p<0.01$} & \multicolumn{2}{|c|}{$\chi^{2}=427.1 ; p<0.01$} \\
\hline \multicolumn{9}{|c|}{ Respondent's age at marriage } \\
\hline$<18$ & $37.5 \%$ & $62.5 \%$ & $33 \%$ & $67 \%$ & $40.8 \%$ & $59.2 \%$ & $37.9 \%$ & $62.1 \%$ \\
\hline \multirow{2}{*}{$\geq 18$} & $32.9 \%$ & $67.1 \%$ & $35.2 \%$ & $64.8 \%$ & $37.6 \%$ & $62.4 \%$ & $33 \%$ & $67 \%$ \\
\hline & \multicolumn{2}{|c|}{$\chi^{2}=16.4 ; p<0.01$} & \multicolumn{2}{|c|}{$\chi^{2}=3.9 ; p<0.05$} & \multicolumn{2}{|c|}{$\chi^{2}=7.8 ; p=<0.01$} & \multicolumn{2}{|c|}{$\chi^{2}=18.4 ; p<0.01$} \\
\hline \multicolumn{9}{|c|}{ Respondent's Education } \\
\hline No education & $37.5 \%$ & $62.5 \%$ & $32.6 \%$ & $67.4 \%$ & $39.4 \%$ & $60.6 \%$ & $36.1 \%$ & $63.9 \%$ \\
\hline Primary & $38.5 \%$ & $61.5 \%$ & $32.8 \%$ & $67.2 \%$ & $41.1 \%$ & $58.9 \%$ & $38.4 \%$ & $61.6 \%$ \\
\hline \multirow[t]{2}{*}{ Secondary +} & $35.4 \%$ & $64.6 \%$ & $34.1 \%$ & $65.9 \%$ & $40.6 \%$ & $59.4 \%$ & $37.1 \%$ & $62.9 \%$ \\
\hline & \multicolumn{2}{|c|}{$\chi^{2}=13.2 ; p<0.01$} & \multicolumn{2}{|c|}{$\chi^{2}=3.4 ; p=0.178$} & \multicolumn{2}{|c|}{$\chi^{2}=2.7 ; p=0.262$} & \multicolumn{2}{|c|}{$\chi^{2}=5.3 ; p=0.07$} \\
\hline \multicolumn{9}{|c|}{ Husband's education } \\
\hline No education & $38 \%$ & $62 \%$ & $32.3 \%$ & $67.7 \%$ & $39.3 \%$ & $60.7 \%$ & $37.3 \%$ & $62.7 \%$ \\
\hline Primary & $38.8 \%$ & $61.2 \%$ & $34.5 \%$ & $65.5 \%$ & $41.7 \%$ & $58.3 \%$ & $39.7 \%$ & $60.3 \%$ \\
\hline \multirow[t]{2}{*}{ Secondary +} & $34.9 \%$ & $65.1 \%$ & $33.2 \%$ & $66.8 \%$ & $40.03 \%$ & $59.7 \%$ & $37.7 \%$ & $64.3 \%$ \\
\hline & \multicolumn{2}{|c|}{$\chi^{2}=21.9 ; p<0.01$} & $\chi^{2}=5.2$ & $p=0.076$ & $\chi^{2}=6$ & $p<0.05$ & $\chi 2=19$ & $p<0.01$ \\
\hline Respondent's Occ & ation & & & & & & & \\
\hline Housewife & $38.7 \%$ & $61.3 \%$ & $34.3 \%$ & $65.7 \%$ & $42.6 \%$ & $57.4 \%$ & $38.8 \%$ & $61.2 \%$ \\
\hline Others & $25.1 \%$ & $74.9 \%$ & $26.9 \%$ & $73.1 \%$ & $26.1 \%$ & $73.9 \%$ & $27 \%$ & $73 \%$ \\
\hline & $\chi^{2}=150$ & $p<0.01$ & $\chi^{2}=45$ & $p=0.01$ & $\chi^{2}=21$ & $4 ; p<0.01$ & $\chi^{2}=113$ & $; \mathrm{p}<0.01$ \\
\hline Type of place of $r$ & dence & & & & & & & \\
\hline Urban & $31.3 \%$ & $68.7 \%$ & $28.6 \%$ & $71.4 \%$ & $31.8 \%$ & $68.2 \%$ & $28.7 \%$ & $71.3 \%$ \\
\hline Rural & $38.9 \%$ & $61.1 \%$ & $34.9 \%$ & $65.1 \%$ & $43.4 \%$ & $56.6 \%$ & $40.3 \%$ & $59.7 \%$ \\
\hline & $\chi^{2}=78$ & $p<0.01$ & $\chi^{2}=57$ & $p<0.01$ & $\chi^{2}=17$ & $3 ; p<0.01$ & $\chi^{2}=18$ & $3 ; \mathrm{p}<0.01$ \\
\hline NGO membership & & & & & & & & \\
\hline No & $38 \%$ & $62 \%$ & $36.8 \%$ & $63.2 \%$ & $43 \%$ & $57 \%$ & $39.2 \%$ & $60.8 \%$ \\
\hline Yes & $35 \%$ & $65 \%$ & $27.1 \%$ & $72.9 \%$ & $35.8 \%$ & $64.2 \%$ & $33.8 \%$ & $66.2 \%$ \\
\hline & $\chi^{2}=14$ & $p<0.01$ & $\chi^{2}=159$ & $p<0.01$ & $\chi^{2}=8$ & $; p<0.01$ & $\chi^{2}=49$ & $p<0.01$ \\
\hline Respondent's relig & & & & & & & & \\
\hline Islam & $37.2 \%$ & $62.8 \%$ & $33.8 \%$ & $66.2 \%$ & $40.6 \%$ & $59.4 \%$ & $37.6 \%$ & $62.4 \%$ \\
\hline Others & $33.9 \%$ & $66.1 \%$ & $28.8 \%$ & $71.2 \%$ & $38.4 \%$ & $61.6 \%$ & $34.3 \%$ & $65.7 \%$ \\
\hline & $\chi^{2}=7.2$ & $<0.05$ & $\chi^{2}=16$ & $p<0.01$ & $\chi^{2}=2$ & $p=0.083$ & $\chi^{2}=6$ & $p=0.08$ \\
\hline
\end{tabular}

EHS: Empowerment in own healthcare seeking, ECHS: Empowerment in child healthcare seeking, ELHP: Empowerment in large household purchase, EVRH: Empowerment in visiting relatives home

extra familiar sources of information and resources, which increase their potential autonomy in family settings. ${ }^{7}$

NGO membership had a significant impact on women's empowerment. Studies found that participation in credit programs is positively associated with a women's level of empowerment defined as a function of their relative physical mobility, economic security, ability to make various purchases on their own freedom from domination and violence within the family, political and legal awareness, and participation in public protests and political campaigning. ${ }^{22}$ In our study, religion had no significant impact on women's empowerment except child healthcare seeking. May be the reason is $90.0 \%$ women were Muslims.

There are a number of limitations of the study. Firstly, the participants of this study were only women. Information from both men and women could generate more reliable information on women's empowerment. Secondly, only four indicators were used to measure women's empowerment in decision making. Thus, the findings do not indicate women's overall empowerment but rather especially focus on these indicators.

\section{Conclusion}

This study is first-to-date to examine the relationship between women's empowerment in health seeking behavior and socio-economic variable. The results of this study indicate the importance of women empowerment trough foraging their health information seeking rights and comprehensive health information management. From the above discussion, we observe that the 
Hasan \& Uddin — Women Empowerment through health seeking behavior

Table 3: Results of logistic regression explaining women's empowerment in decision making by socio-economic characteristics, Bangladesh: BDHS, 2011

\begin{tabular}{|c|c|c|c|c|c|c|c|c|}
\hline \multirow[t]{2}{*}{ Socio-economic variables } & \multicolumn{2}{|c|}{ EHS } & \multicolumn{2}{|c|}{ ECHS } & \multicolumn{2}{|c|}{ ELHP } & \multicolumn{2}{|c|}{ EVRH } \\
\hline & $\boldsymbol{\beta}$ & OR & B & OR & $\boldsymbol{\beta}$ & OR & $\boldsymbol{\beta}$ & $\mathbf{O R}$ \\
\hline \multicolumn{9}{|c|}{ Age of the respondent's (years) } \\
\hline$<25(\mathrm{RC})$ & & 1.00 & & 1.00 & & 1.00 & & 1.00 \\
\hline $25-29$ & $0.599^{*}$ & 1.82 & $1.007^{*}$ & 2.74 & $0.529^{*}$ & 1.698 & $0.487^{*}$ & 1.63 \\
\hline $30-39$ & $0.800^{*}$ & 2.23 & $1.255^{*}$ & 3.51 & $0.839^{*}$ & 2.314 & $0.784^{*}$ & 2.19 \\
\hline$\geq 40$ & $0.625^{*}$ & 1.87 & $1.054^{*}$ & 2.87 & $0.781^{*}$ & 2.183 & $0.798^{*}$ & 2.22 \\
\hline \multicolumn{9}{|c|}{ Respondent's age at marriage } \\
\hline$<18(\mathrm{RC})$ & & 1.00 & & 1.00 & & 1.00 & & 1.00 \\
\hline$\geq 18$ & -0.036 & 0.97 & $-0.339^{*}$ & 0.71 & -0.063 & 0.939 & 0.008 & 1.01 \\
\hline \multicolumn{9}{|l|}{ Respondent's Education } \\
\hline No education (RC) & & 1.00 & & 1.00 & & 1.00 & & 1.00 \\
\hline Primary & 0.084 & 1.08 & $0.252^{*}$ & 1.29 & $0.132^{* *}$ & 1.141 & 0.073 & 1.08 \\
\hline Secondary+ & $0.301^{*}$ & 1.35 & $0.455^{*}$ & 1.58 & $0.318^{*}$ & 1.374 & $0.214^{*}$ & 1.24 \\
\hline \multicolumn{9}{|l|}{ Husband's education } \\
\hline No education (RC) & & 1.00 & & 1.00 & & 1.00 & & 1.00 \\
\hline Primary & -0.003 & 0.99 & -0.037 & 0.96 & -0.078 & 0.925 & -0.058 & 0.94 \\
\hline Secondary + & 0.054 & 1.06 & -0.050 & 0.95 & $-0.128^{* *}$ & 0.879 & 0.025 & 1.03 \\
\hline \multicolumn{9}{|l|}{ Respondent's Occupation } \\
\hline Housewife $(\mathrm{RC})$ & & 1.00 & & 1.00 & & 1.00 & & 1.00 \\
\hline Others & $0.551^{*}$ & 1.73 & $0.221^{*}$ & 1.25 & $0.627^{*}$ & 1.87 & $0.416^{*}$ & 1.52 \\
\hline \multicolumn{9}{|l|}{ Place of residence } \\
\hline Urban (RC) & & 1.00 & & 1.00 & & 1.00 & & 1.00 \\
\hline Rural & $-0.23^{*}$ & 0.79 & $-0.276^{*}$ & 0.76 & $-0.443^{*}$ & 0.642 & $-0.451^{*}$ & 0.64 \\
\hline \multicolumn{9}{|l|}{ NGO membership } \\
\hline No (RC) & & 1.00 & & 1.00 & & 1.00 & & 1.00 \\
\hline Yes & 0.083 & 1.09 & $0.356^{*}$ & 1.43 & $0.233^{*}$ & 1.263 & $0.198^{*}$ & 1.22 \\
\hline \multicolumn{9}{|l|}{ Respondent's religion } \\
\hline Islam (RC) & & 1.00 & & 1.00 & & 1.00 & & 1.00 \\
\hline Others & 0.049 & 1.05 & $0.143^{* * *}$ & 1.15 & -0.008 & 0.992 & 0.042 & 1.04 \\
\hline
\end{tabular}

$\mathrm{RC}=$ Reference category, $(*)=$ Significant at $\mathrm{p}<0.001,(* *)$ Significant at $p<0.05$

EHS: Empowerment in own healthcare seeking, ECHS: Empowerment in child healthcare seeking, ELHP: Empowerment in large household purchase, EVRH: Empowerment in visiting relatives home

middle aged women, higher educated women, women in urban areas, and working women are more empowered in decision-making. All possible efforts must be made to increase women's educational level. Government efforts should be made to enhance the employment of women and should encourage women to participate in NGO activities. Special awareness programs should be introduced for rural women to improve their economic status, to increase their educational level, and to participate in their household's decision. The implementation of these recommendations is essential for achieving the targets for the Sustainable Development Goals (SDGs).

\section{Conflict of Interest}

None declared.

\section{References}

1. United Nations (UN). Sustainable Development Knowledge Platform. https:// sustainabledevelopment.un.org/?menu $=1300$ (accessed June 2016)

2. National Institute of Population Research and Training (NIPORT). Bangladesh Demographic and Health Survey 2011. Dhaka: Mitra and Associates, and ICF International, 2013.
3. Abada T, Tenkorang EY. Women's autonomy and unintended pregnancies in the Philippines. J Biosoc Sci 2012;44:703-18.

4. Mosedale S. Assessing women's empowerment: towards a conceptual framework. J Int Dev 2005;17:243-57.

5. Faridi MZ, Chaudhry IS, Anwar M. The socioeconomic and demographic determinants of women work participation in Pakistan: evidence from Bahawapur District. South Asian Studies 2009; 24:351-67.

6. Kabeer N. Gender equality and women's empowerment. A critical analysis of the third millennium development goal 1. Gend Dev 2005; 13: 13-24.

7. Mainuddin AKM, Begum H A, Rawal Lal B, Islam A, Islam SM S. Women Empowerment and Its Relation with Health Seeking Behavior in Bangladesh. J Fam Repr Health 2015;9:65-73

8. Koenig MA, Jamil K, Streatfield PK, Saha T, Al-Sabir A, Arifeen SE . Maternal health and care-seeking behavior in Bangladesh: findings from a national survey. Int Fam 
Plann Perspect 2007;33:75-82.

9. Chant SH. Gender, generation and poverty: exploring the feminization of poverty in Africa, Asia and Latin America. Cheltenham: Edward Elgar Publishing, 2007.

10. Hausmann R, Tyson LD, Zahidi S. The Global Gender Gap Report: Ranking and Scores. Geneva, Switzerland: World Eco For 2011.

11. Camerini L, Schulz PJ, Nakamoto K. Differential effects of health knowledge and health empowerment over patients' selfmanagement and health outcomes: a crosssectional evaluation. Pat Edu Coun 2012;89:337 -44 .

12. Rodwell CM. An analysis of the concept of empowerment. $J A d v$ Nurs 1996;23:305-13.

13. Hermansson E, Mårtensson L. Empowerment in the midwifery context-a concept analysis Midwifery 2011;27:811-6.

14. Holmström I, Röing M. The relation between patient-centeredness and patient empowerment: a discussion on concepts. Pat Edu Coun 2010;79:167-72.

15. Conner KO, Copeland VC, Grote NK. Mental health treatment seeking among older adults with depression: the impact of stigma and race. $A m J$ Ger Psy 2010;18:531.
16. Cline RJ, Haynes KM. Consumer health information seeking on the Internet: the state of the art. Health Edu Res 2001;16:671-92.

17. National Institute of Population Research and Training (NIPORT), Bangladesh Demographic and Health Survey 2007. Dhaka: Mitra and Associates, and Macro International, 2009.

18. Hosmer DW. Lemeshow S.Applied Logistic Regression. New York, John Wiley 1989.

19. Sathar ZA, Kazi S. Women's autonomy in the context of rural Pakistan. Pak Dev Rev 2000;39: $89-110$.

20. Chaudhry IS, Faridi MZ, Anjum S. The Effects of Health and Education on Female Earnings: Empirical Evidence from District Vehari. Pak $J$ Soc Sci 2010;30:109-24.

21. Ashraf J, Ashraf B. Estimating the gender wage gap in Rawalpindi city. J Dev Stud 1993;29: 365 $-76$.

22. Husain Z, Mukerjee D, Dutta M. Are women self -help group members economically more empowered in leftrun municipalities? Dev in Prac 1996; 23:107-22. 